\title{
Gêneros orais nos liuros didáticos: mapeando a diversidade textual/discursiva presente nas escolas públicas brasileiras ${ }^{1}$
}

Orality in books: mapping the diversity of oral genders present in brazilian public schools

Débora Amorim Gomes da Costa-Maciel Universidade de Pernambuco - UPE ORCID: http://orcid.org/0000-0002-6408-1626 Fabrini Katrine da Silva Bilro Secretaria de Educação do Estado de Pernambuco - SEE-PE Tânia Guedes Magalhães Universidade Federal de Juiz de Fora - UFJF DOI: https://doi.org/10.5902/2176148539542

Resumo: Neste trabalho, temos o objetivo de investigar a diversidade de gêneros orais disponível nos livros didáticos de alfabetização, avaliados pelo Programa Nacional do Livro Didático (PNLD) em suas edições 2007, 2010, 2013 e 2016, e compreender quais capacidades de linguagem os gêneros priorizados podem desenvolver. Os dados foram analisados à luz da perspectiva qualitativa (BARDIN, 2016). 0 aporte teórico fundou-se em Schneuwly e Dolz (2004), dentre outros. Os resultados apontaram para um aumento na ocorrência de gêneros orais, ao longo das quatro edições do PNLD, com uma diversidade que propicia o desenvolvimento de capacidades de linguagem variadas.

Palavras-chave: Gêneros orais. Livro didático. Guia do livro didático de alfabetização e letramento.

Abstract: In this paper, we aim to investigate the diversity of oral genres available in literacy textbooks, assessed by the National Textbook Program (PNLD) in its 2007, 2010, 2013 and 2016 editions, and to understand which language skills the prioritized genres can develop. The data were analyzed in the light of the qualitative perspective (BARDIN, 2016). The theoretical support was based on Schneuwly and Dolz (2004), among others.

1 Este trabalho contou com o financiamento de pesquisa do CNPQ/UPE. 


\section{Débora Amorim \\ Gomes da \\ Costa-Maciel \\ Fabrini \\ Katrine da \\ Silva Bilro \\ Tânia Guedes \\ Magalhães}

The results pointed to an increase in the incidence of oral genres throughout the four PNLD editions, with a diversity that allows the development of varied language skills.

Keywords: Oral genres. Textbook. Guide to literacy textbook.

\section{Introdução}

Neste trabalho, mapeamos a diversidade de gêneros textuais/discursivos orais presentes nas resenhas avaliativas dos livros didáticos, voltados à Alfabetização e Letramento, avaliados pelo Programa Nacional do Livro Didático (PNLD). Nesse percurso, elegemos como objetivos específicos: investigar a frequência com que os gêneros aparecem no eixo da oralidade; e compreender quais capacidades de linguagem os gêneros orais priorizados podem desenvolver nos anos de alfabetização.

Em busca de atingir os objetivos visados, analisamos 115 (cento e quinze) resenhas avaliativas emitidas pelo Guia do Livro Didático, anos de alfabetização e letramento, em suas edições de 2007, 2010, 2013, 2016. Os dados foram organizados a partir da contabilização da frequência com que cada gênero oral apareceu em cada edição do Programa, no eixo da oralidade, e analisados à luz da perspectiva qualitativa de investigação (BARDIN, 2016). Nesse caminho, encontramos a possibilidade de investigar e de interpretar o significado dos fenômenos educativos, a partir da compreensão dos modos e contextos em que se estabelecem as interações.

Destacamos a importância do objeto em questão, uma vez que o Governo Federal se compromete em enviar às escolas públicas brasileiras livros didáticos destinados à formação dos(as) alunos(as) e à prática pedagógica do docente, em todos os anos e modalidades de ensino. A aquisição e distribuição dessas obras, além de representar um investimento financeiro do governo - em 2019, por exemplo, foram mais de um milhão de reais, segundo dados do Fundo Nacional de Desenvolvimento da Educação (BRASIL, 2019) -, configuram-se como uma carta de intenção para o processo de ensino-aprendizagem, já que os livros apresentam um projeto de formação dos sujeitos. Investigá-los, portanto, é uma demanda necessária, dado o papel que assume no campo educacional.

No Brasil, os livros didáticos, antes de adentrarem as escolas públicas brasileiras, são oficialmente avaliados, apresentados aos professores(as) e adquiridos pelo Programa Nacional do Livro Didático (PNLD). Esta política pública desenvolvida pelo Ministério da Educação (MEC) divulga em seu Guia de Livros Didáticos resenhas/pareceres das 
obras aprovadas, o que auxilia o(a) docente a identificar as potencialidades apresentadas por cada obra/coleção e a selecionar aquela que mais se aproxima às demandas do seu grupo-sala.

De posse do Guia do PNLD, os(as) professores(as) têm acesso, dentre outras informações, ao repertório de gêneros orais e escritos que estão disponíveis em cada obra. Com isso, têm a possibilidade de compreender quais gêneros são priorizados em cada ano e quais capacidades de linguagem poderão ser desenvolvidas pelos aos alunos(as). Nessa direção, é válido acrescentar que os gêneros textuais/discursivos, no contexto pedagógico, assumem uma dupla função: orientar a prática do(a) professor(a) quanto ao que avaliar em seus alunos e alunas; e permitir ao discente produzir seus textos considerando as práticas sociais de uso da língua, e nesse movimento, dominar os gêneros usados nos

Gêneros orais nos livros didáticos mais diversos contextos sociais (SCHNEUWLY e DOLZ, 2004, p. 28.), o que ressalta ainda mais a importância de compreendermos quais gêneros são disponibilizados pelos manuais que chegam às escolas.

Em se tratando dos gêneros orais, a análise do repertório ofertado é ainda mais relevante. De acordo com o Pacto Nacional pela Alfabetização na Idade Certa (2015b), apesar dos docentes terem consciência da importância dos(as) alunos(as) terem acesso a uma diversidade de gêneros no ciclo de alfabetização, tendem a achar que o trato com a oralidade pode ser uma prática dispensável, por as crianças trazerem isso de suas vivências sociais. Esse posicionamento, na maior parte das vezes, reduz o trabalho com o oral a uma abordagem espontânea e não sistemática, que não possibilita aos alunos(as) o desenvolvimento e a ampliação de grande parte das capacidades de linguagem necessárias à sua participação e interação nos variados contextos (MAGALHÃES e CRISTOVÃO, 2018).

Ao ofertar um repertório de gêneros orais a serem trabalhados, os livros didáticos podem sinalizar caminhos ao docente para o planejamento do ensino do oral, ajudando-os a compreender que "Alfabetizar na perspectiva do letramento também é compreender que se ensina para que as crianças sejam sujeitos capazes de expor, argumentar, explicar, narrar, além de escutar atentamente e opinar, respeitando a vez e o momento de falar" (BRASIL, 2012, p. 11). Isso porque a ampliação das práticas de oralidade significa dar ao aluno(a) o direito de apreender um instrumento necessário não apenas ao ambiente escolar, mas, principalmente, à vida em sociedade.

Em face ao que nosso texto se compromete, organizamos este artigo da seguinte forma: inicialmente, situamos teoricamente as refle- 
xões em torno dos gêneros textuais/discursivos orais e o livro didático.

Débora Amorim Em seguida, apresentamos a diversidade de gêneros orais que compõe Gomes da as obras aprovadas no PNLD 2007, 2010, 2013 e 2016 e, por fim, acresCosta-Maciel cemos uma discussão sobre quais capacidades de linguagem os gêneros priorizados pelas obras podem desenvolver.

Fabrini

Katrine da

1 Gêneros orais e livros didáticos: fundamentos teóricos

Silva Bilro

Tânia Guedes

Magalhães

Para investigarmos os gêneros orais disponíveis nos livros didáticos de alfabetização, partimos da compreensão de que estamos tratando de práticas sociais interativas, que se materializam predominantemente na realidade sonora (MARCUSCHI, 2010). De acordo com Schneuwly e Dolz (2004), os gêneros, orais ou escritos, são megainstrumentos, atividades de linguagem complexas, que permitem uma intervenção didática direcionada, ao possibilitar a descrição e a compreensão das capacidades próprias, no caso do nosso trabalho, capacidades do oral.

No contexto didático, essa compreensão possibilita a ampliação e o desenvolvimento de capacidades discursivas que permitem aos sujeitos reconhecerem e escolherem, de maneira consciente, os recursos comunicativos necessários à sua participação nas situações sociais de interação, pois, além de auxiliarem o trabalho docente, os gêneros orais servem para abordar as diferentes práticas de linguagem e a heterogeneidade textual; contribuem para a análise das condições sociais de produção e recepção de textos; e oferecem um quadro de análise dos conteúdos, da organização do conjunto do texto e das sequências que o compõem, das unidades linguísticas e das características específicas da textualidade (MELO; MARCUSCHI e CAVALCANTE, 2012).

Schneuwly e Dolz (2004) entendem que ao selecionar, ao longo de um ano letivo, uma variedade de gêneros com características composicionais, sociodiscursivas e linguísticas, relativamente diferentes entre si, o(a) docente contribuirá para a ampliação das múltiplas operações de linguagem e para o alargamento das diversas práticas de letramento. Essa realidade impõe a necessidade de uma compreensão docente acerca desses saberes, ou seja, de que aspectos e através de que estratégias é possível tratar os gêneros orais no ambiente escolar, já que não podemos compreender ou tratar determinado objeto "sem um quadro de referências que oriente nosso olhar e dê sentido às observações" (p.115). 
No processo de escolha dos gêneros a serem tomados como objetos de ensino, o livro didático acaba subsidiando, de maneira significativa, a prática docente ao ofertar um repertório de gêneros e de conteúdos a serem aprendidos, de sugestões e de direcionamentos acerca do desenvolvimento das atividades a serem realizadas. Nesse sentido, Bunzen (2014) afirma que o livro didático é um objeto cultural que procura sistematizar e organizar os conhecimentos escolares na forma de modelo(s) didático(s) e, por isso mesmo, representa valores que participam do processo de socialização e aculturação do público a quem ele se destina.

Ao tratar dos modelos didáticos, Dolz e Gagnon (2015) se referem à Gêneros orais nos livros descrição e à seleção das principais características ensináveis de um gênero, didáticos tendo como objetivo orientar e intermediar as intervenções didáticas dos docentes. Ao assumir essa função, não basta apenas os livros didáticos trazerem as características próprias a cada gênero; é preciso que elenquem os aspectos que possibilitam o seu ensino e a sua compreensão pelos alunos(as), considerando "os saberes de referência que precisam ser mobilizados para se trabalhar com os gêneros; a descrição dos diferentes componentes textuais específicos; as capacidades linguageiras dos alunos" (p.40).

Se forem capazes de possibilitar a inter-relação entre a dimensão teórica, as competências que se espera que sejam dominadas pelos alunos(as) e os objetivos de ensino, as propostas de ensino dos gêneros orais, apresentadas pelos livros didáticos, podem revelar uma multiplicidade de saberes que servirão como referência ao ensino do oral, assim como também podem se constituir em um recurso significativo na escolha dos gêneros a serem ensinados, na formulação dos propósitos, dos objetivos e dos meios através dos quais os docentes atenderão às demandas colocadas por seu grupo-sala.

É importante ressaltar que, antes de serem adquiridos para o uso escolar, os livros didáticos são submetidos a um processo avaliativo imposto pelo Programa Nacional do Livro Didático (PNLD). Após a aprovação, as obras passam a compor o Guia de Livros Didáticos e são apresentadas aos(as) professores(as), de modo panorâmico, através de resenhas, o que possibilita aos(às) docentes escolherem as coleções que melhor atendam às demandas dos seus alunos(as).

Há uma preocupação explícita com a qualidade e o repertório de gêneros que chegam à escola a partir dos livros didáticos. Embora não seja mencionada uma abordagem padronizada, do ponto de vista teórico-metodológico, por exemplo, o programa deixa claro que os livros devem 
Débora Amorim

Gomes da

Costa-Maciel

Fabrini

Katrine da

Silva Bilro

Tânia Guedes

Magalhães

248

“explicitar clara e corretamente as concepções de língua/linguagem e de ensino-aprendizagem que adota, assim como os princípios teórico-metodológicos assumidos e os objetivos da proposta didático-pedagógica" (BRASIL, 2015, p. 17). Esse também é um critério que tem suas implicações na seleção feita pelos autores(as) de livros didáticos sobre o repertório de gêneros textuais/discursivos disponibilizados nas obras.

Existem diferentes caminhos teórico-metodológicos de abordagens do ensino dos gêneros, dentre eles, a perspectiva interacionista sociodiscursiva, cujos pressupostos iluminaram os Parâmetros Curriculares Nacionais, na década de 1990, e parece guiar, junto a outras propostas teóricas, no tempo presente, a Base Nacional Curricular Comum (2018). Schneuwly e Dolz são autores de referências dessa teoria e propõem caminhos possíveis para que os(as) alunos(as) dominem com maestria os diferentes textos de tipos e gêneros diversos.

Dentro das propostas, esses teóricos apresentam a perspectiva do Agrupamento de Gêneros como instrumento para a construção da progressão que norteará o ensino. Para cada agrupamento são apontados três critérios que servem para determinar a coerência mínima da proposta com as referências externas:

1) domínios sociais de comunicação: “correspondem às grandes finalidades sociais legadas ao ensino, respondendo as necessidades de linguagem em expressão escrita e oral, em domínios essenciais de comunicação em nossa sociedade (inclusive a escola)" (SCHNEUWLY e DOLZ, 2004, p. 50).

2) aspectos tipológicos: "retomam, de maneira flexível, certas distinções tipológicas, que já figuram em manuais e guias curriculares" (SCHNEUWLY e DOLZ, 2004, p. 50).

3) capacidades de linguagem dominantes: "sejam relativamente homogêneos quanto às capacidades de linguagem implicadas no domínio dos gêneros agrupados" (SCHNEUWLY e DOLZ, 2004, p. 50).

A partir desses critérios, foram organizados cinco agrupamentos tipológicos e suas capacidades de linguagem, compreendidas nas ordens do narrar (mimeses da ação através da criação da intriga no domínio do verossímil); do relatar (representação pelo discurso de experiências vividas, situadas no tempo); do argumentar (sustentação, refutação e negociação de tomadas de posição); do expor (apresen- 
tação textual de diferentes formas de saberes); e do descrever ações ${ }^{2}$ (regulação mútua de comportamentos). Tais capacidades organizam os gêneros em função de certo quantitativo de regularidades linguísticas, para definir capacidades globais a serem construídas ao longo da escolarização (SCHNEUWLY e DOLZ, 2004).

A proposta é que cada agrupamento seja trabalhado em todos os níveis da escolaridade, pois esse encaminhamento oferece aos alunos(as) vias diferentes de acesso ao oral e à escrita; oferece a possibilidade de definir as especificidades de cada gênero por meio da comparação de textos, porque "trata-se de um princípio elementar de construção por confronto com o mesmo e o diferente."; ainda possibilita desenvolver as capacidades dos aprendizes em domínios diversos, desde a linguagem como instrumento de aprendizagem até a linguagem como "mimeses

Gêneros orais nos livros didáticos da ação a serviço da reflexão sobre a relação do homem com o mundo e consigo mesmo" (SCHNEUWLY e DOLZ, 2004, p.53).

Nesse sentido, este modelo milita por uma proposta escolar que contemple a diversidade de gêneros presentes no cotidiano das práticas sociais, na integração entre oralidade e escrita. A lógica de progressão de gêneros visa aprimorar e desenvolver nos sujeitos o domínio dos gêneros organizados em agrupamentos, bem como possibilitar ao professor(a) ter uma maior compreensão do que deve ser planejado em sala de aula para os seus alunos(as).

Com base nessa compreensão, acreditamos que a organização/ seleção dos gêneros textuais/discursivos pelos livros didáticos endereça intenções de uma proposta formativa. Ou seja, quando um conjunto de textos/gêneros são apresentados em uma obra, ela anuncia para as escolas e para o(a) professor(a) o sujeito que deseja desenvolver, quem pretende formar. É nessa direção e com essa inquietação que nosso trabalho se debruça sobre esta temática, observando o que foi proposto pelos livros didáticos em relação ao repertório de gêneros orais, para as crianças pertencentes às escolas públicas brasileiras, em fase de alfabetização.

Aportadas nessa base teórica, sigamos para a análise e discussão dos dados.

2 Por ter este agrupamento a capacidade de "regulação mútua de comportamentos", alguns autores o denominam "instruir" ou conjunto de textos instrucionais (como afirmam GARCIA-REIS; BOTELHO; MAGALHÃES, 2017, baseadas em diferentes autores). 
Débora Amorim

Gomes da

Costa-Maciel

Fabrini

Katrine da

Silva Bilro

Tânia Guedes

Magalhães

250

\section{Mapeando a diversidade de gêneros orais presentes}

nas escolas públicas brasileiras: análise dos dados

Os dados a seguir foram gerados a partir de uma tentativa de mapear a diversidade de gêneros orais que circulam nos livros didáticos enviados, pelo Ministério da Educação, às escolas públicas brasileiras, ao longo de 9 (nove) anos; e de perceber que capacidades de linguagem esses gêneros podem desenvolver nos(as) alunos(as) em fase de alfabetização.

Vemos que no ano de 2007, as obras aprovadas pelo PNLD apresentaram um conjunto de 23 (vinte e três) gêneros da oralidade. Nas obras, predominam os gêneros: conversa (17), relatos (11), reconto (9), discussão (8), entrevista (6), debate (5), exposição oral (5). Outros gêneros também aparecem, embora em menor quantidade; são eles: história (4), notícias (4), adivinha (2), cantigas (2), declamação de poesia (1), descrição de brinquedos (3), diálogo (2), fábula (2), parlenda (2), peça teatral (1), poema (2), propaganda (1), quadrinhas (1), regra de jogo (1), reportagem (1), trava-língua (1).

A edição 2010 do PNLD apresenta 39 (trinta e nove) gêneros. Aqueles de maior predominância são: relato (13), cantiga (11), parlenda (11), trava-língua (11), reconto (9), conversa (6), entrevista (7), história (9), poema (6), quadrinha (6), piada (5). Outros gêneros orais que aparecem em menor quantidade são: adivinha (3), biografia (1), brincadeira (2), brinquedo cantado (1), canção (2), comentário (3), contação de história (3), conto (1), convite (1), curiosidade (1), debate (3), descrição (2), diálogo (1), discussão (1), encenação de história (2), explicação (2), exposição de ponto de vista (1), fábula (1), instrução (1), jogo (1), jogral (2), música (3), opiniões (3), poesia (1), recital (2), regras de jogo (1), respostas orais (1), texto de opinião (4).

Em 2013, o PNLD apresentou um quantitativo de 36 (trinta e seis) gêneros textuais/discursivos. Entre eles, os que aparecem com maior frequência são: entrevista (14), debate (11), exposição/ apresentação/seminário oral (17), conversa (9), relato (de pesquisa/ orais) (9), discussão (6), poemas (10), parlenda (7), reconto (6), opiniões (5), quadrinha (5), trava-língua (5), dramatização (5), cantiga de roda (5), peça teatral/fantoche (5). Aqueles de menor frequência são os gêneros: adivinha (3), anedota (2), campanha publicitária (1), causo (1), contação de história (4), conto (4), versos (2), depoimento (1), diálogo (2), fábula (1), explicação de brinquedos (2), história 
(3), jogral (3), notícia de jornal (2), piada (2), poesia (1), regras de jogo (1), telefonema (1), pesquisa oral (2), votação oral justificada (1), avaliação oral de atividade (1).

No PNLD 2016, são apresentados 35 (trinta e cinco) gêneros orais. Os de maior projeção são: debate (8), dramatização (8), entrevista (8), exposições/apresentações (11), parlenda (5), poema (8), recontos (8), cantiga de roda (6), relatos (6), trava-língua (5). Os demais gêneros orais apresentam uma frequência mais baixa, são eles: adivinhas (1), anedota (1), história (3), piada (2), contos (3), convite (2), depoimento (1), diálogo (1), discussões (2), fábula (1), jingle (1), jogral (3), lenda (1), memórias (1), peça teatral (2), pesquisa escolar (1), poesia (3), produção de narrativas orais (1), quadrinha (3), registros de entrevistas (1), regras de brincadeiras (2), roda de conversa (1), roda de histórias (1) e seminário (1), mensagem de voz para celular (1).

De modo geral, vemos que há um aumento no quantitativo de gêneros orais ao longo das edições do PNLD. Assim temos: no ano de 2007, 23 (vinte e três); no ano de 2010, 39 (trinta e nove) gêneros; no ano de 2013, 36 (trinta e seis); no ano de 2016, 35 (trinta e cinco), conforme mostra o quadro abaixo. 


\begin{tabular}{|c|c|c|c|}
\hline \multicolumn{4}{|c|}{ Débora Amorim } \\
\hline Gomes da & ANO & QUANTIDADE & GÊNEROS DA ORALIDADE \\
\hline $\begin{array}{r}\text { Costa-Maciel } \\
\text { Fabrini } \\
\text { Katrine da } \\
\text { Silva Bilro }\end{array}$ & 2007 & 23 & $\begin{array}{l}\text { conversa (17), relatos (11), reconto (9), discussão (8), entrevis- } \\
\text { ta (6), debate (5), exposição oral (5), história (4), notícias (4), } \\
\text { adivinha (2), cantigas (2), declamação de poesia (1), descrição } \\
\text { de brinquedos (3), diálogo (2), fábula (2), parlenda (2), peça } \\
\text { teatral (1), poema (2), propaganda (1), quadrinhas (1), regra } \\
\text { de jogo (1), reportagem (1), trava-língua (1) }\end{array}$ \\
\hline $\begin{array}{r}\text { Tânia Guedes } \\
\text { Magalhães }\end{array}$ & 2010 & 39 & $\begin{array}{l}\text { relato (13), cantiga (11), parlenda (11), trava-língua (11), re- } \\
\text { conto (9), conversa (6), entrevista (7), história (9), poema (6), } \\
\text { quadrinha (6), piada (5), adivinha (3), biografia (1), brinca- } \\
\text { deira (2), brinquedo cantado (1), canção (2), comentário (3), } \\
\text { contação de história (3), conto (1), convite (1), curiosidade (1), } \\
\text { debate (3), descrição (2), diálogo (1), discussão (1), encenação } \\
\text { de história (2), explicação (2), exposição de ponto de vista (1), } \\
\text { fábula (1), instrução (1), jogo (1), jogral (2), música (3), opini- } \\
\text { ões (3), poesia (1), recital (2), regras de jogo (1), respostas orais } \\
\text { (1), texto de opinião (4). }\end{array}$ \\
\hline \multirow{2}{*}{252} & 2013 & 36 & $\begin{array}{l}\text { entrevista (14), debate (11), exposição/apresentação/semi- } \\
\text { nário oral (17), conversa (9), relato (de pesquisa/orais) (9), } \\
\text { discussão (6), poemas (10), parlenda (7), reconto (6), opiniões } \\
\text { (5), quadrinha (5), trava-língua (5), dramatização (5), cantiga } \\
\text { de roda (5), peça teatral/fantoche (5). Aqueles de menor fre- } \\
\text { quência são os gêneros: adivinha (3), anedota (2), campanha } \\
\text { publicitária (1), causo (1), contação de história (4), conto (4), } \\
\text { versos (2), depoimento (1), diálogo (2), fábula (1), explicação } \\
\text { de brinquedos (2), história (3), jogral (3), notícia de jornal } \\
\text { (2), piada (2), poesia (1), regras de jogo (1), telefonema (1), } \\
\text { pesquisa oral (2), votação oral justificada (1), avaliação oral } \\
\text { de atividade (1). }\end{array}$ \\
\hline & 2016 & 35 & $\begin{array}{l}\text { debate (8), dramatização (8), entrevista (8), exposições/apre- } \\
\text { sentações (11), parlenda (5), poema (8), recontos (8), cantiga } \\
\text { de roda (6), relatos (6), trava-língua (5). Os demais gêneros } \\
\text { orais apresentam uma frequência mais baixa, são eles: adivi- } \\
\text { nhas (1), anedota (1), história (3), piada (2), contos (3), convi- } \\
\text { te (2), depoimento (1), diálogo (1), discussões (2), fábula (1), } \\
\text { jingle (1), jogral (3), lenda (1), memórias (1), peça teatral (2), } \\
\text { pesquisa escolar (1), poesia (3), produção de narrativas orais } \\
\text { (1), quadrinha (3), registros de entrevistas (1), regras de brin- } \\
\text { cadeiras (2), roda de conversa (1), roda de histórias (1) e semi- } \\
\text { nário (1), mensagem de voz para celular (1). }\end{array}$ \\
\hline
\end{tabular}

Fonte: elaborado pelas autoras

Ao analisarmos esses gêneros a partir da perspectiva do agrupamento, proposta por Schneuwly e Dolz (2004), percebemos que, ao longo de todas as edições, há a presença de gêneros situados nos cinco agrupamentos (narrar, relatar, argumentar, expor e descrever ações). Assim, temos: 
Edição de 2007 - ordem do narrar, 11 (onze) gêneros; ordem do argumentar, 5 (cinco) gêneros; ordem do relatar, 3 (três) gêneros; ordem do expor, 2 (dois) gêneros; ordem do descrever ações, 2 (dois) gêneros.

Edição 2010 - ordem do narrar, 18 (dezoito) gêneros; ordem do argumentar, 9 (nove) gêneros; ordem do descrever ações, 6 (seis) gêneros; ordem do expor, 4 (quatro) gêneros; ordem do relatar, 2 (dois) gêneros.

Edição 2013 - ordem do narrar, 17 (dezessete) gêneros; ordem do argumentar, 9 (nove) gêneros; ordem do relatar, 5 (cinco) gêneros; ordem do expor, 3 (três) gêneros; ordem do descrever ações, 2 (dois) gêneros.

Edição 2016 - ordem do narrar, 18 (dezoito) gêneros; ordem do Gêneros orais nos livros argumentar, 7 (sete) gêneros; ordem do expor, 5 (cinco) gêneros; ordem didáticos do relatar, 4 (quatro) gêneros; ordem do descrever ações, 1 (um) gênero.

o quadro abaixo reúne as informações acima para melhor visualização:

Quadro 2: agrupamentos presentes nos Guias nos anos 2007 a 2016

\begin{tabular}{|c|c|c|}
\hline ANO & AGRUPAMENTO & QUANTIDADE \\
\hline \multirow{5}{*}{2007} & narrar & 11 \\
\hline & argumentar & 5 \\
\hline & relatar & 3 \\
\hline & expor & 2 \\
\hline & descrever ações & 2 \\
\hline \multirow{5}{*}{2010} & narrar & 18 \\
\hline & argumentar & 9 \\
\hline & relatar & 2 \\
\hline & expor & 4 \\
\hline & descrever ações & 6 \\
\hline \multirow{5}{*}{2013} & narrar & 17 \\
\hline & argumentar & 9 \\
\hline & relatar & 5 \\
\hline & expor & 3 \\
\hline & descrever ações & 2 \\
\hline \multirow{5}{*}{2016} & narrar & 18 \\
\hline & argumentar & 7 \\
\hline & relatar & 4 \\
\hline & expor & 5 \\
\hline & descrever ações & 1 \\
\hline
\end{tabular}

Fonte: elaborado pelas autoras 
A presença de gêneros dos cinco agrupamentos, ao longo de todas as

Débora Amorim

Gomes da

Costa-Maciel

Fabrini

Katrine da

Silva Bilro

Tânia Guedes

Magalhães

edições do PNLD, revela-nos uma preocupação em ofertar uma variedade de atividades, que oportunizem aos estudantes o contato com as diversas tipologias textuais, assim como a compreensão dos domínios sociais em que se dá a comunicação e o desenvolvimento das diferentes capacidades de linguagem. No entanto, apesar disso, ao analisarmos a diversidade de gêneros, percebemos que algumas ordens predominam mais que outras. Isso nos faz compreender, consequentemente, que algumas capacidades de linguagem são mais priorizadas. A ordem do narrar, que busca desenvolver a capacidade de realizar "mimeses da ação através da criação da intriga no domínio verossímil" (SCHNEUWLY e DOLZ, 2004, p. 51) é a que recebe mais ênfase, sendo em todas as edições a que apresenta um maior número de gêneros.

Os gêneros que mais se projetam ao longo dos anos são: conversa (17), relatos (11), reconto (9), discussão (8), entrevista (6), debate (5), exposição oral (5) na edição 2007; relato (13), cantiga (11), parlenda (11) e trava-língua (11), reconto (9), conversa (6), entrevista (7), história (9), poema (6), quadrinha (6), piada (5), na edição 2010; entrevista (14), debate (11), exposição/apresentação/seminário oral (17), conversa (9), relato (de pesquisa/orais) (9), discussão (6), poemas (10) parlenda (7) e reconto (6), opiniões (5), quadrinha (5), trava-língua (5), dramatização (5), cantiga de roda (5), peça teatral/fantoche (5), na edição 2013; debate (8), dramatização (8), entrevista (8), exposições (6), parlenda (5), poema (8), recontos (8), cantiga de roda (6), relatos (6) e trava-língua (5), apresentação de ora - programa de TV/receita (2)/trabalho - (5), na edição 2016.

Entre os gêneros de maior destaque nas obras avaliadas nas 4 (quatro) edições do PNLD, a entrevista (37) e o relato (39) aparecem em todas as edições e prevalece em termos quantitativos. O cenário pode nos revelar a seguinte preocupação das obras: no que diz respeito ao gênero reconto, parece haver uma preocupação das obras avaliadas em investir em gêneros da ordem do relatar, que diz respeito à capacidade de "representação pelo discurso de experiências vividas, situadas no tempo". No que diz respeito à entrevista, parece haver uma preocupação das obras avaliadas em investir em gêneros da ordem do expor, que compreende a capacidade de "apresentação textual de diferentes formas de saberes" (SCHNEUWLY e DOLZ, 2004, p. 52), apesar de sabermos que a entrevista pode ser de diferentes naturezas ${ }^{3}$ (MARCUSCHI, 2008) .

3 As entrevistas podem ser de especialista, de seleção, médica, pessoal, jornalística, dentre outras. 
Devemos registrar que, em todas as edições, o PNLD apresenta o reconto (32) como um gênero textual, embora saibamos que a atividade de recontar é uma "reconstrução oral de um texto já existente", cujo "principal procedimento é a imitação a partir de um texto modelo: um conto clássico, anúncio, texto expositivo, uma notícia, entre outros". Recontar implica dizer de forma parecida "com o que estava no livro, no jornal, na revista, no encarte, ou como se fosse o autor. O propósito é a adesão ao texto selecionado, respeitando seu tipo de linguagem, as marcas do gênero, o tema e a sua estrutura" (SÁ, 2019, p.1).

Os gêneros poema (24), parlenda (23), trava-língua (21), debate (24), exposição oral (33) e conversa (32), embora apareçam em grande quantidade, não estão presentes em todas as edições. O poema, o trava-língua e a parlenda, por exemplo, não são localizados na edição 2007.

Gêneros orais nos livros didáticos Como sabemos, ambos são gêneros da ordem do narrar, representativos da cultura oral. A sua ausência desperta em nós algumas inquietações, como, por exemplo, qual o motivo da ausência desses gêneros nas 24 (vinte e quatro) obras aprovadas na referida edição? Estariam elas privilegiando gêneros mais formais, conforme sinalizam os Parâmetros Curriculares Nacionais (1997), documento norteador de currículo, lançado na mesma década?

Gostaríamos também de chamar atenção para os gêneros debate (24) e exposição oral (33), ausentes na edição de 2010; conversa (32), ausente na edição 2016 e cantiga (22), ausente na edição 2007. Vemos assim a edição 2010 privando os(as) alunos(as) de gêneros mais formais, de base argumentativa e expositiva, o que poderia provocar em nós as seguintes indagações: o que levaria um conjunto de 24 (vinte e quatro) coleções, não investir nesses gêneros que demandariam uma maior preparação por parte dos(as) alunos(as) para o uso da fala pública formal? Devemos registrar que, ao tratarmos de gêneros da ordem do argumentar, estamos favorecendo a ampliação da capacidade de "sustentação, refutação e negociação de tomadas de posição" (SCHNEUWLY e DOLZ, 2004, p. 52), a qual os(as) alunos(as), ainda que em idade tenra, de alguma forma já possuem.

Para Brandão, Leal e Nascimento (2011, p. 148), por exemplo, “A argumentação se dá a partir do momento em que é provável a emergência de opiniões controversas sobre um determinado tema". É um trabalho que envolve, sistematicamente, o nosso engajamento na produção de textos que revelem o que pensamos, que defendam a nossa opinião e que nos faça, dentre outras questões, repensar sobre as nossas ações. 
Débora Amorim

Gomes da

Costa-Maciel

Fabrini

Katrine da

Silva Bilro

Tânia Guedes

Magalhães

256

Destacamos também o gênero conversa (32), cuja frequência é uma das maiores ao longo de três edições. A ausência desse gênero na última edição do PNLD pode representar diferentes questões, dentre elas: o amadurecimento das coleções no trato com os gêneros que necessitam de um maior investimento no planejamento da fala. Em geral, o gênero conversa é usado nos livros em momentos mais espontâneos para discussões sobre determinado tema (COSTA-MACIEL, 2006).

Assim como a conversa, alguns gêneros não ocorrem em todas as edições: opiniões (5), piada (5) e história (9) aparecem apenas na edição 2010; a quadrinha (11), apenas em 2010 e 2013; e a discussão (14), apenas 2007 e 2013. Esses gêneros aparecem entre uma escala de 5 a 14 ocorrências, em uma ou duas edições do PNLD. Destes, apenas a quadrinha aparece em duas edições consecutivas, 2010 e 2013. Vemos que são gêneros de tradição oral e que há uma interrupção na presença deles, conforme destacamos. Não sabemos determinar o que faz com que essas obras não ofertem um conjunto de gêneros de tradição oral. Estariam elas, nesses anos em específico, menos voltadas para a valorização dessa cultura?

Remetamo-nos agora aos demais gêneros, ao longo das edições, que aparecem em menor ocorrência: uma variação que vai de 1 a 4 , são prevalentemente gêneros informais, em sua maioria, criados na base da tradição oral; exemplos: fábula, parlenda, poema, jogral, música, roda de conversa. Observamos, pontualmente, a presença, entre os gêneros de menor quantidade, aqueles de âmbito formal, dentre eles: notícias, propaganda e reportagem, no ano de 2007; debate, no ano de 2010; campanha publicitária e notícia de jornal, na edição 2013; seminário, na edição 2016.

Para finalizar essa análise, desejamos destacar os gêneros telefonema, na edição 2013 e mensagem de voz para celular, na edição 2016. Tratam-se de gêneros já dominados pelos(as) alunos(as) e que podem funcionar como ponto de partida para a ampliação de outras capacidades, necessárias a outros gêneros ainda não dominados por eles(as).

\section{Considerações}

Neste artigo, mapeamos a diversidade de gêneros textuais/discursivos orais presentes nas resenhas avaliativas dos livros didáticos de alfabetização, avaliados pelo Programa Nacional do Livro Didático (PNLD), em suas edições 2007, 2010, 2013 e 2016. E buscamos compreender quais capacidades de linguagem os gêneros orais priorizados pelas obras mobilizam nos anos de alfabetização. 
Os resultados apontaram para um aumento na ocorrência de gêneros orais, ao longo das quatro edições do PNLD analisadas. No ano de 2007 foram 23 (vinte e três) gêneros; no ano de 2010, 39 (trinta e nove); no ano de 2013, 36 (trinta e seis); e no ano de 2016, 35 (trinta e cinco). 0 repertório de gêneros orais apresenta uma diversidade que varia, em maior frequência, no âmbito dos gêneros formais, e em maior quantidade, no contexto de gêneros informais. É um cenário que pode propiciar o desenvolvimento de capacidades de linguagem variadas, já que se nota a presença de gêneros situados nos cinco agrupamentos (narrar, relatar, argumentar, expor e descrever ações).

Essa diversidade pode apontar para a produção de um objeto cultural que desenha propostas didáticas e objetivos aos(às) alunos(as) que estão matriculados nas escolas públicas brasileiras. Não temos como

Gêneros orais nos livros didáticos dizer sobre o conjunto de textos suportados nesses gêneros, uma vez que não há condições de fazermos esse tratamento a partir do cenário traçado pelo PNLD, em suas diferentes edições. Contudo, podemos apresentar a diversidade de gêneros e supor quais capacidades de linguagem poderiam ser desenvolvidas, a partir do agrupamento de gêneros a que pertencem. E, com isso, afirmar que a oferta desse repertório, com algumas prevalências, é uma carta de intenção formativa aos sujeitos que estão nas escolas públicas.

Sendo assim, se temos a consciência de que os livros didáticos têm um papel garantido pelo Ministério da Educação e que eles adentram as salas de aula visando ser explorados pelos agentes do sistema de ensino-aprendizagem, ou seja, educador/educando; e, se temos os gêneros textuais/discursivo como cruciais ao auxílio de novas propostas de alfabetização, eficazes na formação de leitores(as) e produtores(as) de textos capazes ampliar o seu papel de cidadão(ã), percebemos que o mapeamento revelado por nossa pesquisa nos dá um cenário favorável a esse processo. 


\section{REFERÊNCIAS}

Débora Amorim

Gomes da BARDIN, L. Análise de conteúdo. Tradução de Luís Antero Reto e Costa-Maciel

Fabrini Katrine da Silva Bilro

Tânia Guedes Magalhães

Augusto Pinheiro. São Paulo: Edições 70, 2016.

BRASIL. Secretaria de Educação Fundamental. Parâmetros curriculares nacionais: língua portuguesa/ Secretaria de Educação Fundamental. - Brasília. 1996.

MEC. Guia do livro didático PNLD 2007: alfabetização: séries/anos iniciais do ensino fundamental / Secretaria de Educação Básica. - Brasília: Ministério da Educação, Secretaria de Educação Básica, 2006.

. MEC. Guia de livros didáticos PNLD 2010: Letramento e Alfabetização/Língua Portuguesa. - Brasília: Ministério da Educação, Secretaria de Educação Básica, 2009.

. SEF/MEC. Guia do livro didático: Língua Portuguesa: alfabetização e letramento (PNLD 2013). Brasília: MEC/SEF, 2013.

. MEC. Guia de livros didáticos PNLD 2016: letramento e alfabetização e língua portuguesa / ensino fundamental anos iniciais. Ministério da Educação. - Brasília, MEC: 2015a. (aqui vai ser A pq tem outro BRASIL 2015 abaixo)

Secretaria de Educação Básica. Diretoria de Apoio à Gestão Educacional. Pacto Nacional pela Alfabetização na Idade Certa. Planejamento escolar: alfabetização e ensino da língua portuguesa. Ano 1: unidade 2. Ministério da Educação, Secretaria de Educação Básica, Diretoria de Apoio à Gestão Educacional. - Brasília: MEC, SEB, 2012.

Secretaria de Educação Básica. Diretoria de Apoio à Gestão Educacional. Pacto Nacional pela Alfabetização na Idade Certa. Caderno 05: a oralidade, a leitura e a escrita no ciclo de alfabetização. Ministério da Educação, Secretaria de Educação Básica, Diretoria de Apoio à Gestão Educacional. - Brasília: MEC, SEB, 2015b. Diferenciar BRASIL 2015. 
Base Nacional Comum Curricular (BNCC). Brasília: MEC. 2018. Disponível em: < http://basenacionalcomum.mec.gov.br/images/ BNCC_18jun_site.pdf > Acesso em: 18 junho 2019.

. Fundo Nacional de Desenvolvimento da Educação. Disponível em: <http://www.fnde.gov.br/programas/livro-didatico/livro-didatico-dados-estatisticos>. Acesso em: 18 de junho de 2019.

BUNZEN, Clécio. Análise de Livros Didáticos de Portuguesa no Campo da Linguística Aplicada: Possibilidades e Desafios. In: GONÇALVES, A. V.; SILVA, W. R.; GÓIS, M. L. de S. (Org.). Visibilizar a Linguística Aplicada: Abordagens Teóricas e Metodológicas. 1ed.Campinas: Pontes, 2014, p. 269-292.

Gêneros orais nos livros didáticos

COSTA-MACIEL, D. A. G. Livros Didáticos de Língua Portuguesa: Propostas didáticas para o ensino da linguagem oral. UFPE, Recife/ PE. Dissertação de mestrado, 2006.

DOLZ, J.; GAGNON, R. O gênero de texto, uma ferramenta didática para desenvolver a linguagem oral e escrita. In: BUENO, L.; COSTA-HÜBES, T. da C. (Orgs.). Gêneros orais no ensino. Campinas, SP: Mercado de Letras, 2015. p. 23-56.

BRANDÃO, A. C. P.; LEAL, T. F.; NASCIMENTO, B. E. Aprendendo a argumentar: o ensino da oralidade nos livros didáticos de alfabetização. In: MARCUSCHI, B.; LEAL, T. F (Orgs.). Estudos sobre educação e linguagem: da educação infantil ao ensino médio. Recife: Ed. Universitária da UFPE, 2011.

GARCIA-REIS, A. R.; BOTELHO, L. S.; MAGALHÃES, T. G. (Orgs). Leitura e escrita de textos instrucionais. Recife: Pipa Comunicação, 2017.

MAGALHÃES, T. G.; CRISTOVÃO, V.L.L. Oralidade e ensino de Língua Portuguesa. Campinas, SP: Editora Pontes, 2018.

MARCUSCHI, L. A. Da Fala para a Escrita: atividades de retextualização. São Paulo: Cortez, 2001. 


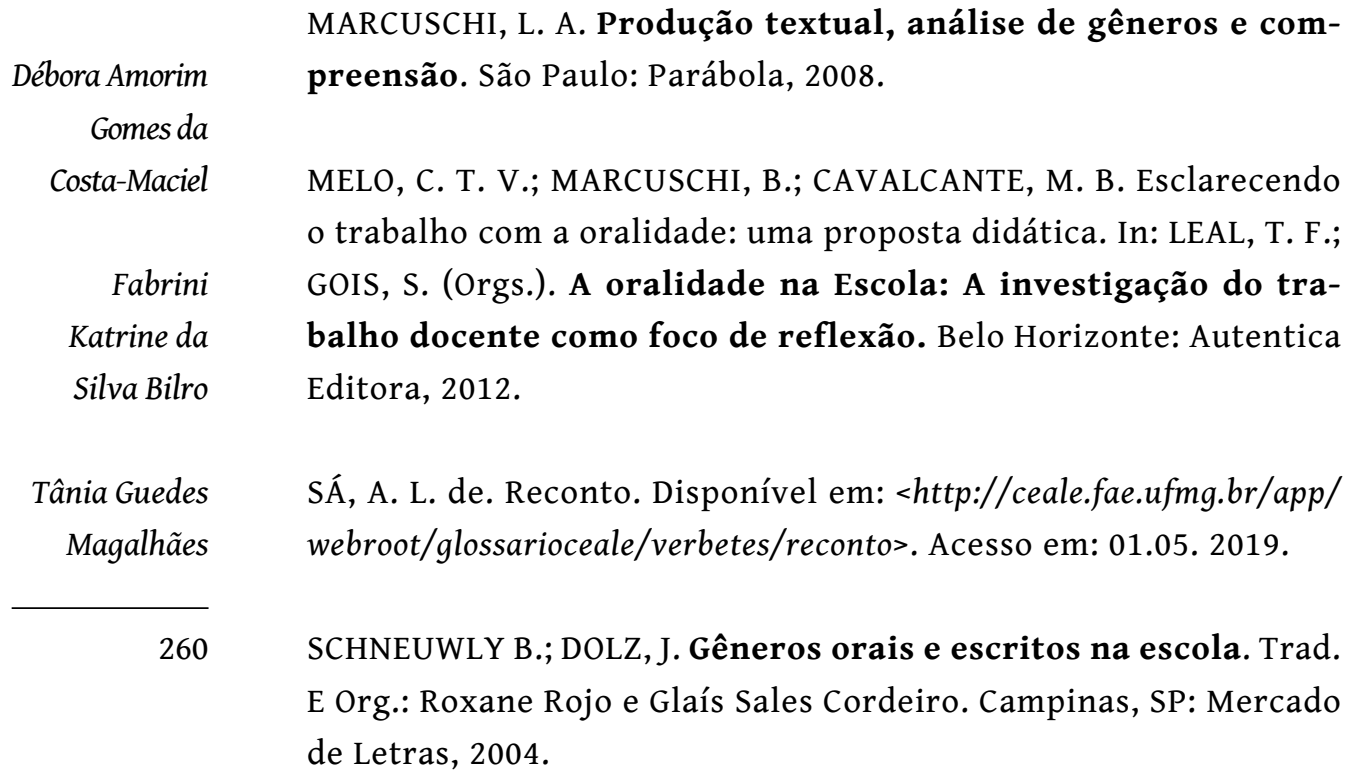

MARCUSCHI, L. A. Produção textual, análise de gêneros e compreensão. São Paulo: Parábola, 2008.

MELO, C. T. V.; MARCUSCHI, B.; CAVALCANTE, M. B. Esclarecendo GOIS, S. (Orgs.). A oralidade na Escola: A investigação do traKatrine da balho docente como foco de reflexão. Belo Horizonte: Autentica Silva Bilro Editora, 2012.

ânia Guedes SÁ, A. L. de. Reconto. Disponível em: <http://ceale.fae.ufmg.br/app/ tras, 2004 